\title{
The importance of a comprehensive method in the teaching of literary translation
}

\author{
N. Berrin Aksoy*
}

\begin{abstract}
The emergence of translation studies as an independent discipline contributed to the development of the pedagogy of translation included in a number of higher education programmes. Due to its unique status as a creative and aesthetic product, literary text and its translation into a foreign language and culture deserve a comprehensive method which consists of a balance of theory and practice of literary translation. This paper deals with how such a balance should be established in the teaching of literary translation to the future translators of literature in higher education programmes.
\end{abstract}

Keywords: literary text, translation theory, translation practice, literary translation

\section{Introduction}

Translation as a pedagogical branch was widely used in language teaching especially since the Grammar-Translation method which dominated the classroom for some years. Basically, the method consisted of teaching grammatical rules and then applying those rules mechanically in translating the foreign language into the mother tongue or vice versa. The use of translation in teaching in such a way had nothing to do with teaching translation of course, since the aim was to teach a foreign language by making use of translation as one of the teaching methods. Beginning with the development of communication systems and international exchange in all spheres of life, the importance of translation gained ground as an unchallenged bridge in all human contact. Hence, the need for translation as a profession and consequently, a methodological, scientific approach to teaching translation. The emergence of translation studies as a separate discipline on its own contributed to the development of teaching methods that is in James Holmes' terms "the pedagogy of translation in 1970's". Nowadays, teaching translation has become one of the applied branches of descriptive translation studies and is taken up in many academic journals and studies.

\section{Analysis \& Discussion}

Teaching translation is closely linked with the theories of translation. Translation theories have been specifically developed for literary translation as a process and product. Since literary translation is different from other types of translation due

\footnotetext{
* Atılım University, Department of Translation and Interpretation, Ankara, Turkey.
} 
to its stylistic and aesthetic qualities, it is very important to have a theoretical background in order to understand and overcome the challenges in literary translation. Hence, the increase in literary translation degree programmes is an indication of the necessity of teaching literary translation in a methodological and academic framework. In these degree programmes would-be translators are trained by means of comprehensive methodological tools, practices and theories and they work on a variety of text types. Such a study enables future translators to meet with different types of translation challenges and develop skills to devise strategies to overcome those challenges. Within this frame, the theoretical dimension and practice of literary translation should be well proportioned for a consistent curriculum. If the theoretical dimension weighs more, students will heavily depend on the instructive aspect of translation and will lack the skill to deal with actual translation situations; on the other hand, focusing on only the practice dimension prevents students from creating a foundation for the skills he / she is employing at a particular instance; theory helps students to become aware of what they do in practice and has solid reasons, purposes, as well as outcomes and functions. Also, theoretical knowledge enables the student to reflect upon and to evaluate his / her translation approach, and the function it is going to have in the target language.

Translation students must be well acquainted with knowledge of language above all, and a wide knowledge of the cultural background of the text in order to fully grasp the context of the text with all its linguistic and extralinguistic components. In the teaching of literary translation, context and background information mining is a prerequisite which must be materialized in the curriculum by means of a multidisciplinary approach. Since in literary translation the translator undertakes the task of recreating the effects created by the use of multi-layered shades and levels in the original text, students should be guided towards carrying out a variety of research and study in order to gain information on the context and the background.

Language and linguistic knowledge are two important pillars in all kinds of translation teaching be it literary or scientific. Theory and theoretical studies of linguistics and language create an awareness of how language is used and should be used in the source and target situations and with such a background, equivalences can be more clearly established at both ends. Hence, to make an outline of the content of theoretical teaching translation theory such a curriculum should equip students with the earliest discussions of translation with respect to language and literary studies; teach the various stages of the development of linguistically oriented translation theories and their relation with linguistics; inform the students of the cultural turn in translation studies and how and why culture should be emphasized in all studies and practices of literary translation; elaborate on the descriptive translation studies in order to teach students to become aware of the process of translation and why and how certain texts have 
been translated in one way or other at a particular time; postcolonial translation studies should also be included in the syllabus to teach students how to know about the reflections of some ideological issues such as hegemony, colonialism on the process and product of translation; and the future of translation studies in line with the developments in an interdisciplinary sphere which consists of literature, linguistics, sociology, ideology and the like.

Along with the above theoretical knowledge, in order to teach literary translation with all the qualities and characteristics it entails, it is necessary to teach students first things first, i. e. the nature and constitution of a literary text. To begin with, such an introduction requires the teaching of text types and qualities as well. At this point, Katharine Reiss's text type classification should be dealt with and the expressive type of texts which consists of creative compositions should be very well studied and compared with other text types.

A literary text is, above all, an aesthetic and artistic production aimed to invoke and create certain feelings, impressions and responses on the reader. Students must be able to handle the text with such a background and must learn to carry out an analysis so as to understand how the artistic and aesthetic quality is produced. Language is the foundation of all literary texts. A literary text is composed of literary, linguistic and cultural norms as well as of the unique style of its author. As Jean Boise-Beier writes in her article "Stylistics and Translation", whenever translation is concerned with how something is said as well as what is said, it involves the translation of style (1).

The main challenge of the style of the literary text for the translation student is to develop and possess the necessary information and skills to analyse the metaphorical, figurative meanings, usage, words and intentional ambiguities. In order to translate well, students should be able to grasp the meanings and effects created by that particular style.

For that purpose, stylistic analysis of the literary text should be taught to the students in a methodological manner along with a frame of steps to conduct a general and comprehensive analysis of the text to be translated.

The following steps can be recommended to be taught in the classroom in order to fully posit the literary text in perspective:

Step 1: Read the text thoroughly at least twice.

Step 2: Summarize the text in the classroom either orally or in written form.

Step 3: Identify the addressee of the text and its purpose.

Step 4: Study the author, his / her life, background, the literary and cultural environment they come from. 
Step 5: Identify the purpose of the translation.

Step 6: Find out the content and the theme.

Step 7: Find out the message.

Step 8: Carry out a style analysis of the text to find out how the author uses language to convey an emotional and artistic message with all the qualities peculiar to that author. Step 8 should cover the study of the following qualities: content, theme, grammar, sentence structure, figures of speech such as metaphors, imagery, allegory, allusions etc., rising action, climax, characterization, cultural elements.

Step 9: An overall evaluation of the text and its place and function in the source culture.

These steps are devised to equip the students to be able to grasp the literary text fully in order to decide on the strategies to be used in the process of translation.

After the completion of such a study on the literary text students may be asked to identify a frame for the would-be translation in the target culture. They should be encouraged to ask and give answers to such questions in relation to the translation:

1) Is there a corresponding text-type and genre in the target literary system?

2) Does the target audience share the same expectations and taste about that particular genre? If not what is the difference?

3) Are there similar stylistic devices for the corresponding genre?

4) Are there correspondences in the target culture for the cultural and conceptual elements of the source text?

5) Are there previous translations of that particular text and of the author's works?

6) Is the author known in the target literary system? What kind of image does s/he have?

Discussions in the classroom about what kind of answers should be provided for these questions will greatly help students to choose a strategy to start the translation process. Depending on the answers and the analysis, students, in line with their previous knowledge of methods and procedure of translation, can choose to employ the foreignization or domestication strategy and methods either of these strategies necessitates.

Along with Robert Bly's “The Eight Stages of Translation”, Clifford E. Landers 
in his book Literary Translation develops a typology for literary translation depending on his personal experience as a translator. The steps below or some of them can be a useful typology to employ in the classroom and students can be encouraged to study them and apply them in their translation practices:

(1) Read the entire work at least twice.

(2) Determine the authorial voice. This will affect virtually every choice in the thousands of words to be translated. Note any shifts in tone from one part of text to another.

(3) Do the first draft, marketing troublesome areas in square brackets and/ or bold face for further attention. At this stage there is a relatively less emphasis on smoothness and fluency and more on capturing the semantic gist of the text.

(4) Consult with an educated native speaker to clarify any points that are still vague. For especially vexing items, consult the author.

(5) Revise the manuscript, with emphasis on phraseology, fluency, and naturalness. At this stage it should come as close as possible to reading as if it had been written originally in English.

(6) Have a highly literate native speaker of English, preferably one with no knowledge of the SL, go over the manuscript and indicate any rough spots, i. e. parts that are awkward, stilted, 'translationese,' or that make no sense. Make any necessary changes.

(7) Go over the manuscript line by line with a native speaker of the SL who is also fluent in English.

(8) Make the final changes, run it through a spell-check, and let it rest for a few days. (45-46)

\section{Conclusion}

In conclusion, it has become a widely accepted fact that teaching literary translation in higher education programmes requires a combination of theory and practice in the curricula. The sound theoretical knowledge and consistent practice of translation in the classroom will also make space for the creativity of the students and make them confident about their future profession.

\section{Bibliography}

Reiss 2004. Reiss K. "Type, Kind and Individuality of Text: Decision Making in Translation" In Lawrence Venuti. The Translation Studies Reader. Oxon: Routledge, 2004. 168-179.

Boase. Boase B. J. In "Stylistics and Translation". (1-23). https://www.academia. 
edu/382300/Stylistics_and_Translation

Landers 2001. Landers C. E. Literary Translation: A Practical Guide. Topics in Translation 22. Bassnett S. (ed.). UK: Multilingual Matters, 2001.

Zhang 2016. Zhang Y. "Approaches to Teaching Literary Translation". In US-China Foreign Language. Vol. 14, No 7. July 2016. 512-515.

QGLT. Quick Guide to Literary Translation. The Society of Authors, 84 Drayton Gardens, London SW10 9SB. Available online at < http://www.societyofauthors.org/ sites/default/files/page-not-found $>$ 